\title{
High-Speed Visible Light Communications: Enabling Technologies and State of the Art
}

\author{
Ruonan Ji ${ }^{1,2,3(\mathbb{D})}$, Shaowei Wang ${ }^{2,3, *(\mathbb{D})}$, Qingquan Liu ${ }^{2,3,4}$ and Wei $\mathrm{Lu}^{2,3}$ \\ 1 Department of Applied Physics, Northwestern Polytechnical University, Xi'an 710129, China; \\ jiruonan@nwpu.edu.cn \\ 2 State Key Laboratory of Infrared Physics, Shanghai Institute of Technical Physics, \\ Chinese Academy of Sciences, Shanghai 200083, China; liuqqbit@163.com (Q.L.); \\ luwei@mail.sitp.ac.cn (W.L.) \\ 3 Shanghai Engineering Research Center of Energy-Saving Coatings, Shanghai 200083, China \\ 4 School of Physics and Technology, ShanghaiTech University, Shanghai 201210, China \\ * Correspondence: wangshw@mail.sitp.ac.cn; Tel.: +86-21-2505-1864
}

Received: 3 January 2018; Accepted: 30 March 2018; Published: 9 April 2018

\begin{abstract}
In the nearest decades, the rapidly increasing demand of wireless connectivity has resulted in the ubiquitous deployment of wireless systems as well as heavily congested wireless spectrum. Owing to the various inherent advantages, such as spectral and bandwidth relief, no healthy concern, high security, low cost, and low interference with Radio Frequency (RF) waves, visible light communication (VLC) has been an emerging optical wireless data transmission approach that can act as a good complement to and substitute for Radio Frequency. How to achieve a high-speed data transmission is a key problem to be solved in the VLC system. This review mainly focuses on the enabling technologies for high-speed VLC systems, including novel transmitter architectures, blue filters and advanced modulation, and equalization technologies. And the inherent advantages, potential applications, and some issues of VLC that need further study are presented as well. Finally, a comprehensive survey on the recent developments and the key contributions by research groups involved in the field of high-speed VLC is provided.
\end{abstract}

Keywords: visible light communications; high-speed; LED; blue filter; modulation; equalization

\section{Introduction}

Visible Light Communication (VLC) is an emerging optical wireless data transmission approach that using visible lights as the signal carriers. The history of Visible Light Communication could be traced back to the 1880s, when Alexander Graham Bell developed a photophone by modulating sunlight. This invention even pre-dates the transmission of voice data by radio. Several other works using fluorescent lights as the light source for communication were demonstrated then with quite low data rates. According to the reports of Jackson et al., the data rate is only fast enough to refresh a 40-character display 2.5 times per second [1]. With the developments in man-made light sources, the traditional fluorescent lights and incandescent bulbs are gradually being replaced by light emitting diodes (LEDs). Due to the advantage of their lower costs, higher lifetime, low power consumption and high switching rate, LEDs have predominantly become the most favorable light source for VLC. In a LED-based VLC system, information is transmitted by modulating the intensity of LED at a rate much faster than the response time of the human eyes, which offers simultaneous illumination and high-speed data transmission. Therefore, it is regarded as an economic, secure, and ubiquitous data transmission solution, especially a perfect last-mile solution in the future [2]. 
This review mainly focuses on the enabling technologies for high-speed visible light communication systems. It is organized as follows. Section 2 presents the inherent advantages and potential applications of VLC. Section 3 discusses detailed the technical approaches for the improvement of the data rate in a VLC system, including the novel transmitter architectures, optical filters, advanced modulation, and equalization technologies. Section 4 reviews the recent developments and the contributions by research groups involved in the field of VLC. Section 5 lists some issues that must be addressed by in-depth study in future research, and Section 6 presents important conclusions that are drawn from this survey as well as the prospects of the technology.

\section{Potentials of VLC System}

In the nearest decades, wireless connectivity has become one of the basic commodities in our daily life. The rapidly increasing demand for it has resulted in the ubiquitous deployment of wireless systems as well as a heavily congested wireless spectrum that has occurred as a result. In response, VLC has been gaining in popularity as a good complement and substitute for radio frequency due to the following motivations and inherent advantages.

\section{(1) Bandwidth resource}

$\mathrm{RF}$, with a frequency band of $3 \mathrm{kHz}$ to $300 \mathrm{GHz}$, is the most popular frequency band in the modern wireless communication systems. Each wireless communication system independently uses a frequency band to avoid interfere. Since the spectrum resources are limited, national regulation and authorization are usually essential. However, with the rapid growth of wireless communication applications and demand, this authorization and fixed distribution method results in an increasingly dwindling RF spectrum. Developing alternative technologies with larger bandwidth and spectral relief is urgent. Visible light (corresponding to a wavelength band of $380 \mathrm{~nm}$ to $780 \mathrm{~nm}$ ) has 10,000 times a greater spectrum than radio waves [3]. In addition, VLC does not require spectrum regulation and authorization. Thus, in contrast to the RF communication, VLC has huge available and unregulated bandwidth resource for data transmission, making it a potential solution to overcoming the crowded RF spectrum in wireless communication.

(2) Safe

The health hazards of radio frequency have attracted increasing attention. Under long-term exposure to strong electromagnetic radiation, the function of the human body may suffer from a certain degree of hurt. Therefore, wireless communications generally need to limit their own transmitting power, which can greatly affect system performance. VLC uses LEDs emitting white light for lighting, which is the same as natural light, and almost harmless to the human body. Such advantages make VLC communication a popular alternative when health considerations are taken into account.

\section{(3) Security/privacy and interference}

Radio waves can penetrate walls and are susceptible to eavesdropping on in-room or in-building communications. Furthermore, radio waves are susceptible to mutual interference with electronic devices, which greatly limits the scope of their application. Since lights can be strictly confined to an intended area surrounded by opaque boundaries, the security of VLC is greatly enhanced. However, recent research has shown that eavesdropping on VLC is possible, generally by capturing the light signals that leak through the gap between the floor and door, keyhole, and even partially covered windows [4]. Nonetheless, VLC is still a much more secure option than traditional RF communication. In addition, VLC does not cause any interference with RF signals and has no health concerns [5]. Thus this technology is perfectly suitable for a scenario where sensitive electronic devices are used, such as hospitals, or in industrial and aerospace applications [6]. 
(4) Low cost and energy efficient

The cost of VLC devices are comparatively lower than the current RF modules. Study shows that a Bluetooth module, which provides a data rata up to $1 \mathrm{Mb} / \mathrm{s}$, costs about $\$ 5$ while a VLC link can offer a data rate of about $4 \mathrm{Mb} / \mathrm{s}$ with a cost of only around $\$ 1$ per module [7]. Furthermore, LED-based VLC has emerged as a green communication technology because of the excellent energy efficiency feature of LEDs. When compared with traditional lighting technologies, LEDs use less energy [8] and generate less heat [9]. The energy consumption of LED is only $1 / 10$ and $1 / 4$ of the incandescent and fluorescent lighting, respectively. According to a report from the U.S. Department of Energy, SSL technology is promising to conserve up to 217 terawatt-hours (TWh) save energy by the year 2025 [10].

Owing to the inherent benefits outlined above, VLC system has broad application prospects, and different application scenarios are summarized as follows.

(1) Indoor high-speed network access: Li-Fi

The term Li-Fi was coined by Prof Harald Haas from Edinburgh University in 2011. It is a high-speed bi-directional fully connected VLC system analogous to Wi-Fi as shown in Figure 1. A speed of up to $10 \mathrm{~Gb} / \mathrm{s}$ can be obtained using $\mathrm{Li}-\mathrm{Fi}$, which is 250 times more than the speed of 'super-fast' broadband [11]. Due to the problem of interference with other RF signals, Wi-Fi is forbidden or limited in many electromagnetic wave sensitive areas, such as aircrafts, nuclear power plants, and hospitals. Therefore, Li-Fi can be a better solution in such environments as it does not cause any electromagnetic interference. However, as one cannot use light bulbs to send data to fast-moving objects, or objects behind obstacles, $\mathrm{Li}-\mathrm{Fi}$ is not a competitor to Wi-Fi, but a complementary technology that will help to free up spectrum space.

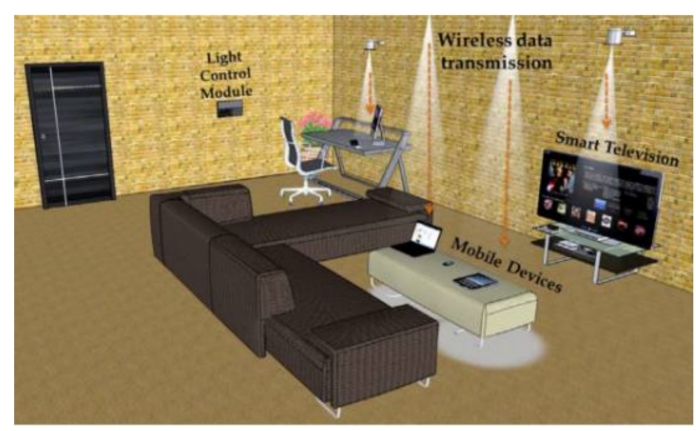

Figure 1. Example of a Li-Fi system. Reproduced with permission from [12], Elsevier, 2017. (Reprinted from Energy Build, 149, Chew, I. etc., Smart lighting: The way forward? Reviewing the past to shape the future. 180-191, Copyright (2017), with permission from Elsevier.)

\section{(2) Underwater communication}

Due to the salty, high conductivity, and high attenuation environment of sea water, RF signals cannot travel well in sea water. Although sound waves travel far in the ocean, they have a low transmission rate, limited bandwidth and high-power consumption. Furthermore, they may interfere with marine animals such as dolphins. VLC uses the visible light of the optical transmission window $(420-510 \mathrm{~nm})$ in seawater for data communication, which can effectively overcome some shortcomings of microwave and sound waves in underwater communication. Thus, VLC can be used to send data to submarines or divers with their head lights and other underwater devices. In 2015, Rust et al. from Massachusetts Institute of Technology (MIT) has applied VLC to their underwater robots' communication and localization in a non-destructive nuclear reactor inspection [13]. The underwater use of VLC now still has some limitations, such as the data rate and distance are obviously affected by hydrological conditions, especially turbidity. For example, Doniec et al. proposed an underwater 
VLC system called AquaOptical [14], which can obtain a data rate of $1.2 \mathrm{Mb} / \mathrm{s}$ over $30 \mathrm{~m}$ in clear water. While in water with visibility estimated at $3 \mathrm{~m}$, the data rates and distances dropped to $0.6 \mathrm{Mb} / \mathrm{s}$ and $9 \mathrm{~m}$.

(3) Intelligent transportation

Congestion has become an increasingly significant issue worldwide, especially in the developing countries, and has leading to a series of problems, such as air pollution, fuel consumption and difficulties in implementing transportation plans. Furthermore, accident risks increase with the rapid growth of the number of vehicles. Malta et al. [15] indicated that almost three fourths of all traffic accidents can be attributed to human error. Thus, one may predict that if there is an early warning system in place, the probability of accidents will be greatly reduced.

The above problem can be alleviated by implementing the intelligent transportation. As shown in Figure 2, VLC could be used to send messages with vehicle lights, traffic lights, street lights and the other elements of the lighting infrastructure. According to the Vehicle Safety Communications Project from the US Department of Transportation, the applications including emergency electronic brake lights, cooperative forward collision warning, pre-crash sensing, lane change warning, curve speed warning, stop sign movement assistant, left turn assistant, traffic signal violation warning, and so on [16].

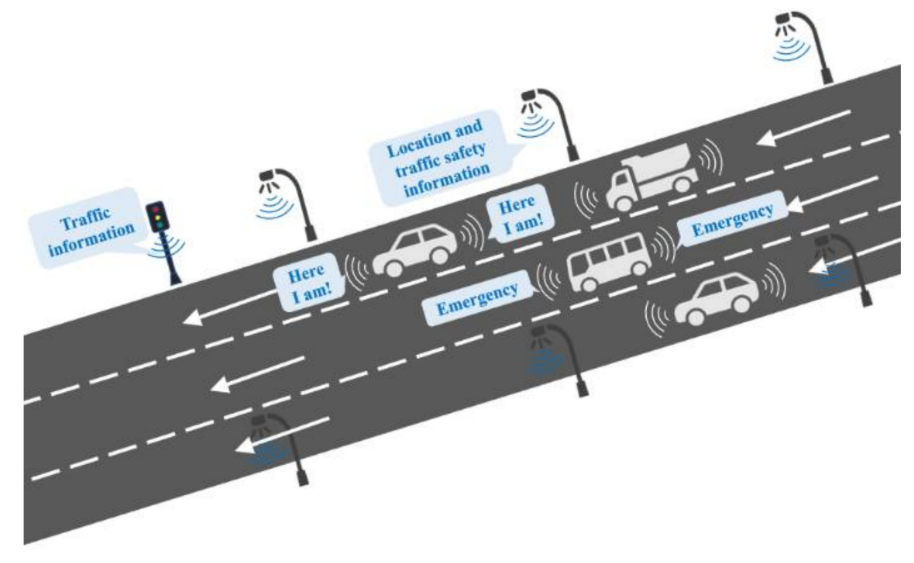

Figure 2. Intelligent transportation scenario.

\section{Enabling Technologies for a High-Speed VLC System}

A typical VLC system includes transmitter, transmission channel and receiver. The transmitter in a VLC system might be a LED or an array of LEDs. The current that flowing through the LEDs is controlled by a driver circuit so that the brightness of the radiated light can be modulated and coded. The signal is transmitted in the free space and then extracted from the modulated light beam by the receiver via signal processing, demodulation, and decoding. The receiver consists of an amplification circuit, optical filter, optical concentrators, photodiode, and a setup for demodulation of the data. And the photodiode can be a silicon photodiode, p-i-n photodiode (PIN) diode, avalanche photodiode (APD) or a camera sensor which converts radiation into photo-current. Both in the transmitter and receiver, equalization technology may be used to further enhance the system capacity. As a high-speed VLC system requires high signal-to-noise-ratio (SNR) values, line-of-sight (LOS) paths are required for most of the applications.

As VLC has numerous inherent advantages and wider application areas when compared to the traditional wireless communication systems, it has drawn much attention from research institutes and companies worldwide, and great development have been achieved as a result. However, it still has some challenges for the VLC system in the practical process, such as a limited achievable data rate due 
to the slow modulation response of LEDs, limited transmission distance caused by the sharp decrease in illumination with distance, multi-path dispersion (MPD), fluorescent light interference (FLI) and so on. Among them, how to achieve high-speed data transmission is one of the hotspots as it is a key problem to be solved in the VLC system. In this section, the possible solutions to improve the data rate are discussed, including novel transmitter architectures, advanced modulation and equalization technology, and optical filters.

\subsection{LED Technology}

White light is the most widely used form of illumination in the common communication applications, such as color rendering [17]. And the most common and cost effective way to produce white light is to use a blue LED with yellow phosphor coating, as shown in Figure 3a [17]. While due to the slow relaxation time of the phosphor coating, the modulation bandwidth is on the order of about $3 \mathrm{MHz}$ [17]. And the limited bandwidth and slow modulation response of LEDs are the key challenges which limit the achievable data rate in VLC. The White light also can be produced with a combination of ultraviolet emitters and multi-color phosphor. Another more attractive way is using separate red-green-blue (RGB) or red-yellow-green-blue (RYGB) emitters, namely, by using RGB or RYGB LED. RGB LED is the most common multi-chip LED, which contains three jointly packaged LED chips (red, green and blue) to produce white lights (see Figure 3b). By changing the light intensities of the different chips, the color of the output light is modified. Since this kind of LEDs avoid the use of phosphor as well as the slow relaxation time, a much higher modulation bandwidth of more than $100 \mathrm{MHz}$ can be obtained. However, the multi-chip LEDs still suffer from some drawbacks, such as having a lower Color Rendering Index3 (CRI), a more complex structure, and higher costs than the traditional phosphor-based LEDs (ps-LEDs).

Besides the above LED technologies, some novel LED architectures and LD transmitters are proposed to improve the modulation bandwidth of the VLC system as well.

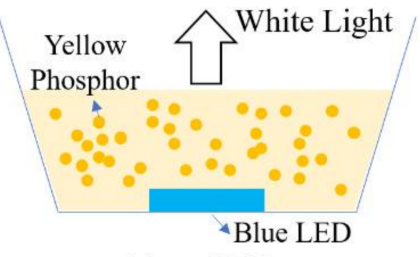

(a) ps-LED

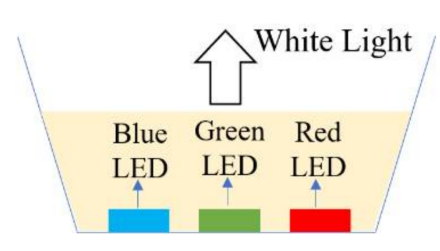

(b) RGB-LED

Figure 3. Schematic diagrams of ps-LED (a) and RGB LED (b).

\section{(1) Resonant Cavity LEDs (RC-LED)}

The light extraction efficiency of the LED refers to the ratio of the output photons to the photons generated by the electron-hole recombination in the active region. In conventional LED devices, the light extraction efficiency is usually less than $10 \%$, due to the factors, such as the substrate absorption, electrode blocking, and total reflection on the out-light surface. Most photons are limited to the inside of the device and are converted into heat, which greatly affects the performance of the device, especially in high power LED devices. To improve light extraction, Bragg reflectors are employed in the LED device to offer high efficiency and high bandwidth, based on the resonant cavity enhancement effect as shown in Figure 4 . The emission of RC-LED is typically at $\sim 650 \mathrm{~nm}$ with a narrow line width and can be modulated in excess of $100 \mathrm{MHz}[18,19]$. Ref [20] demonstrates a AlInGaN based RC-LED that providing the lowest-loss transmission window, around $520 \mathrm{~nm}$, and the bandwidth can level up to $330 \mathrm{MHz}$. With RC-LED, a highly directional output and high data rates of up to $500 \mathrm{Mbps}$ [21] can be obtained, but its fabrication is challenging [22]. 


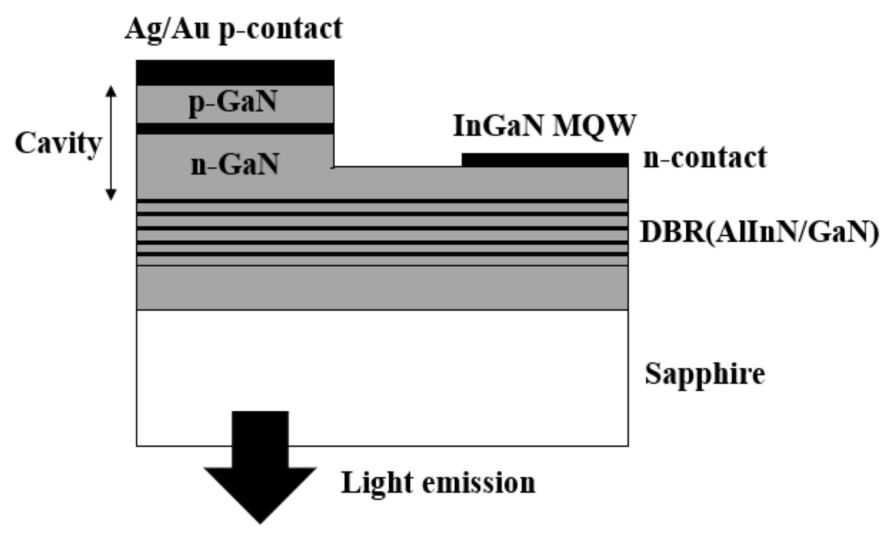

Figure 4. The schematic diagram of a typical RC-LED. Reproduced with permission from [23], John Wiley and Sons, 2004. (Reprinted from Phys. Status Solidi, 201, Dorsaz, J. etc., InGaN/GaN resonant-cavity LED including an AlInN/GaN bragg mirror. 2675-2678, Copyright (2004), with permission from John Wiley and Sons.)

\section{(2) Micro LEDs ( $\mu$-LED)}

Instead of a single LED, micro LEDs consist of arrays of micro-pixelated LED pixels, based on III-nitride Technology. $\mu$-LEDs offer better contrast, response times, longer lifetime, and energy efficiency. More importantly, by reducing the LED active area to $100 \times 100 \mu \mathrm{m}^{2}$ or less, the capacitance is decreased while the current density is increased, and this thereby contributes to a significant increase in the modulation bandwidth. In previous reports, the typical size of each individual pixel rangs from 14 to $84 \mu \mathrm{m}$, and the 3-dB bandwidth can reach $450 \mathrm{MHz}$, which contributs a data rate up to $1.5 \mathrm{~Gb} / \mathrm{s}$ [24-27]. Islim et al. reported a violet micro-LED (shown in Figure 5) with electrical-to-optical bandwidths of up to $655 \mathrm{MHz}$ [28]. With further improvement of these $\mu$-LED sources, researchers from the University of Strathclyde has achieved a high bandwidth that exceeding $800 \mathrm{MHz}$ [29].
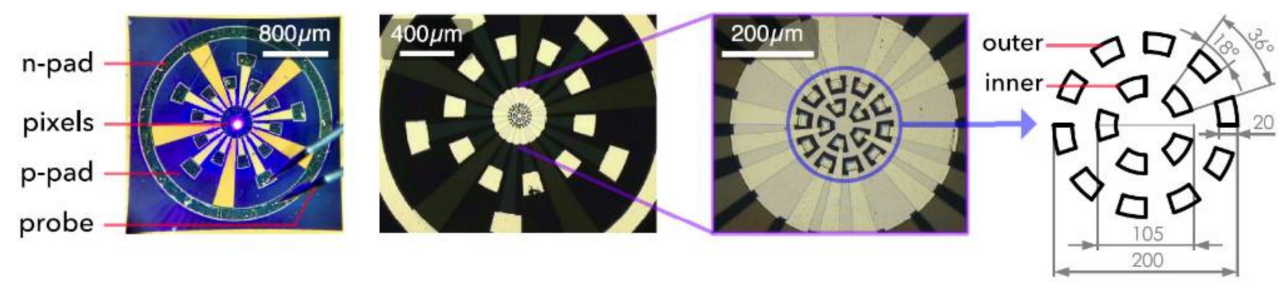

Figure 5. Micro-LEDs proposed in Ref. [28]. Reproduced with permission from [28], Chinese Laser Press, 2017. (Reprinted from Photonics Research, 5, Islim, M. etc., Towards 10 Gb/s OFDM-based visible light communication using a GaN violet micro-LED. A35-A43, Copyright (2017), with permission from Chinese Laser Press.)

\section{(3) Laser diodes (LDs)}

Since it is the photon lifetime, not the carrier lifetime that dominates the dynamics, LDs are capable of handling a data bandwidth enlarged by one or two orders of magnitude greater than LEDs [30]. Thus, in contrast to the limited modulation bandwidth of sub-GHz for LEDs, the modulation bandwidth of LDs is higher than $5 \mathrm{GHz}$ [20]. In addition, LDs has higher current densities and output powers per unit wafer area than LEDs, and recent research has shown that lighting based on multicolor LDs has no health concern on the human eye [31]. Furthermore, the output light has the feature of coherent and collimated, which is fit for point-to-point data transmission. Thus, by leveraging the advantages mentioned above, a LD-based white VLC system is promising to outperform the ones based on LEDs. According to the recent studies, multi-Gigabit data rates have been achieved in VLC 
systems based on III-nitride LDs [15-19]. However, the safety concerns involving the use of LDs is the main limitation for the rapid development of a LD-based VLC system [32].

\subsection{Advanced Modulation}

In VLC, the current flow through the LEDs is controlled by a driver circuit so that the brightness of the radiated light is modulated. By applying advanced high efficient modulation, the limitations of the modulation bandwidth and the transmission data rate are promising to be overcome. Common single carrier modulations include On-Off Keying (OOK), Pulse Position Modulation (PPM), Pulse Width Modulation (PWM), Pulse Amplitude Modulation (PAM) and so on, which have been widely used in IR communications. To realize high data rates, various advanced modulations, such as Orthogonal Frequency Division Multiplexing (OFDM), Carrier-Less Amplitude and Phase Modulation (CAP), Color Shift Keying (CSK), Discrete Multi-Tone (DMT), and Nyquist Single Carrier (N-SC) were proposed.

\section{(1) OFDM}

OFDM is a kind of digital multi-carrier modulation based on a frequency-division multiplexing (FDM) scheme. In OFDM, multiple closely spaced orthogonal subcarriers transmit data on several parallel data streams or channels simultaneously [17]. Each sub-carrier is modulated with a conventional modulation scheme like quadrature amplitude modulation (QAM) or phase shift keying (PSK), followed by a serial to parallel (S/P) converter. Then, they are converts from the frequency domain input signals into time domain output signals by an Inverse Fast Fourier Transform (IFFT). And a cyclic prefix $(\mathrm{CP})$ is added to further limit the effects of inter-channel interference (ICI) and inter symbol interference (ISI). As the VLC signals are unipolar and real, the conventional OFDM needs some modifications. The Hermitian symmetry to generate real-time signals for implementation can be applied at the cost of doubling the required bandwidth. Multiple kinds of modified OFDM schemes were proposed and used in VLC, such as Asymmetrically Clipped Optical OFDM (ACO-OFDM) [33], DC-biased (Direct Current) Optical OFDM (DCO-OFDM) [34], Asymmetrically clipped DC-biased Optical OFDM (ADO-OFDM) [35], and adaptive bit and power loading OFDM [36]. Figure 6 shows the schematic diagram of DCO-OFDM modulation. In ACO-OFDM, an additional DC-bias is not required as the signal is clipped at the zero level [34]. This is because QAM symbols are only assigned to odd subcarriers, and therefore only the even subcarriers suffer from the noise generated by the asymmetrical clipping that occurs below the zero level, while the odd subcarriers are not [34]. Thus, ACO-OFDM reduces the need for a DC-bias and improves the optical power efficiency, but at the cost of giving up half of the spectrum.

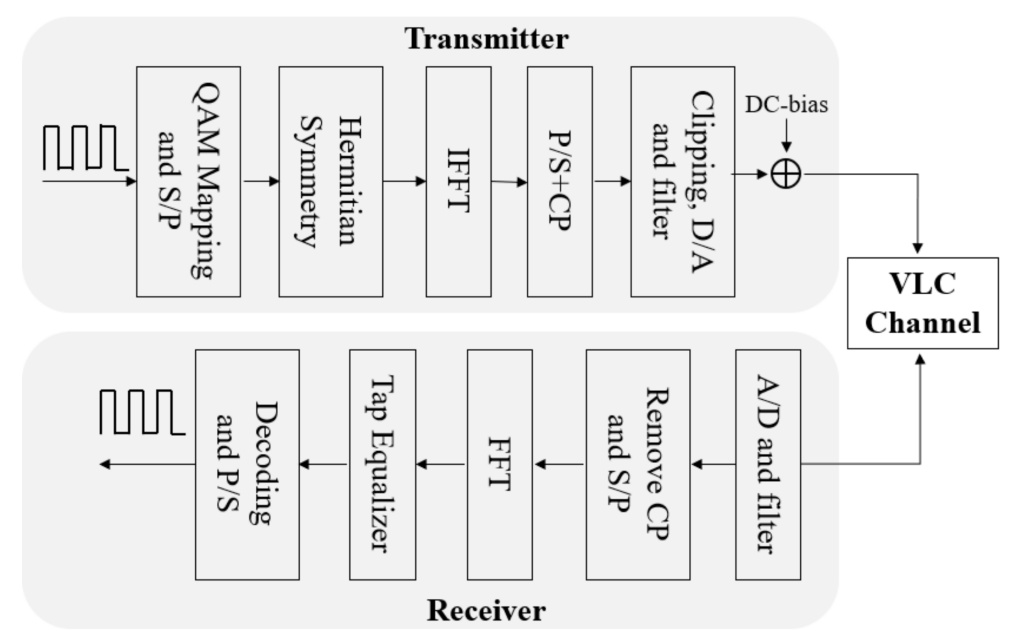

Figure 6. Schematic diagram of DCO-OFDM modulation. 
By combining with higher-order modulation, OFDM bandwidth is highly efficient and can overcome the multipath effects and ISI. However, OFDM also has some shortcomings that cannot be ignored. The non-linearity of LED needs to be considered as it introduces amplitude and phase distortion to significantly affect the performance of the VLC system. Such an impact is more severe in the high order sub-carrier modulation due to a high peak-to-average-power-ratio (PAPR), such as OFDM, and causes the increase of BER and ICI [8]. Such an impact of non-linearity can be minimized by biasing the LEDs in the optimum operation point, limiting the peak-to-peak input signals, and employing power reduction methods, such as signal clipping [37]. And the nonlinearity also can be compensated by applying pre-distortion [38], post-distortion [39], or nonlinear equalization [40].

\section{(2) CAP}

CAP is a kind of high-order multi-dimensional modulation with low complexity and high spectral efficiency, which was proposed by Bell Labs in the 1970s. In a CAP scheme, as shown in Figure 7, the input bit stream is first mapped with Quadrature Amplitude Modulation (QAM), then up-sampled by a factor of $M$, the number of samples per symbol, by inserting $M-1$ zeros between two symbols. The in-phase $(I(t))$ and quadrature $(Q(t))$ sequences are separated and the shaping filters are applied. The outputs of the filers $s(t)$ can be expressed as

$$
s(t)=I(t) \otimes f_{I}(t)-Q(t) \otimes f_{Q}(t)
$$

where $f_{I}(t)$ and $f_{Q}(t)$ are the filter functions of in-phase and quadrature shaping filter. The two orthogonal signals are separated by two matched filters (matched to in-phase and quadrature shaping filters) the. Then down-sampling and signal recovery (including equalization and de-mapping) are carried out to extract the original bit stream. As CAP can be applied without FFT and IFFT blocks, thus, commonly, CAP offers a simpler implementation than OFDM. However, CAP requires a flat-band response for optimum performance, and complex equalizers are necessary for a non-flat spectral system [41], which is less flexible than OFDM [42,43].

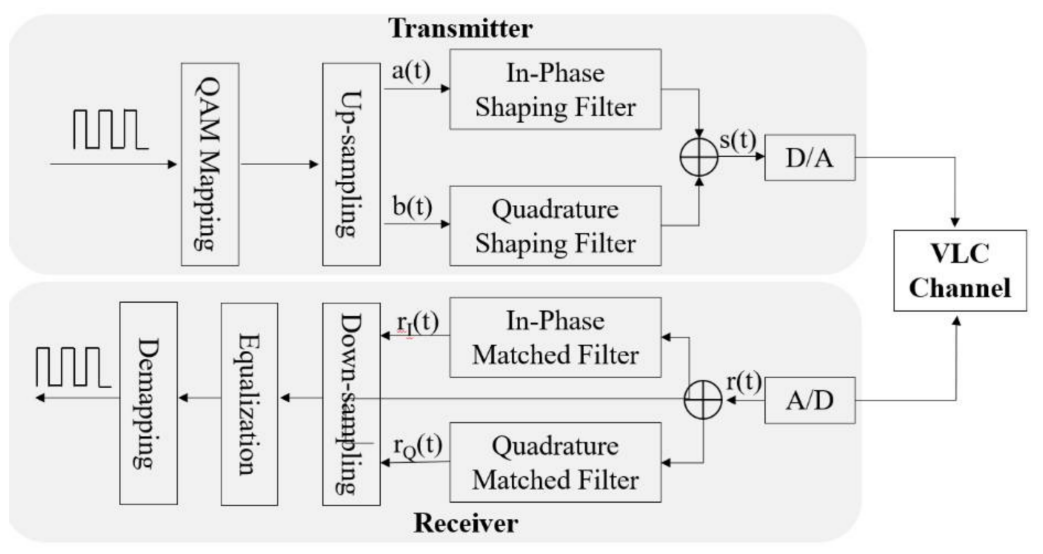

Figure 7. Schematic diagram of CAP modulation. $a(t)$ and $b(t)$ are the original bit sequence after up-sampling. $r(t)$ is the received bit sequence after analogue-to-digital conversion. And $r_{I}(t)$ and $r_{Q}(t)$ are the bit sequence after in-phase and quadrature matched filtering, respectively.

\section{(3) CSK}

CSK is a new modulation method proposed for the visible light communication system that is composed of the red, green, and blue LED sources. As shown in Figure 8, after a scrambler and channel coding, the $x / y$ values are transformed to $p_{i} / p_{j} / p_{k}$ according to the Color mapping constellations (shown in Figure 9). Four color points are defined in the 4-CSK constellation, meaning that 2 bits can be sent with each symbol. Instead of using the absolute intensity of each color in a Wave Division Multiple 
Access (WDMA), CSK uses the intensity ratio of the red, green, and blue colors in the LED source to transmit information, thus it has a higher bandwidth efficiency and data rate, which has attracted significant attention recently [44,45]. And CSK has been included in the IEEE 802.15.7 visible light communication standard modulation. However, according to the above analysis, CSK modulation requires accurate color separation at both the transmitter and the receiver, increasing the complexity of its implementation. And obviously, CSK is not fit for the VLC systems based on pc-LEDs.

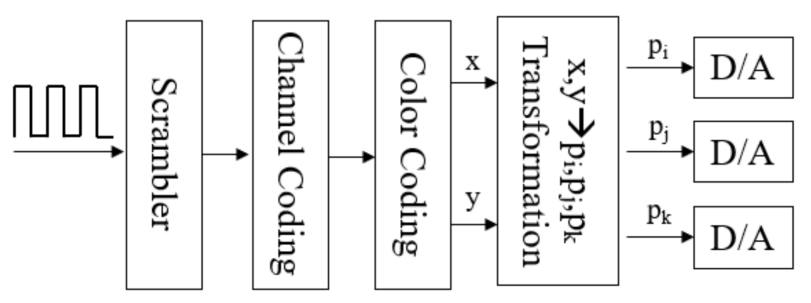

Figure 8. Schematic diagram of the CSK signal generation.

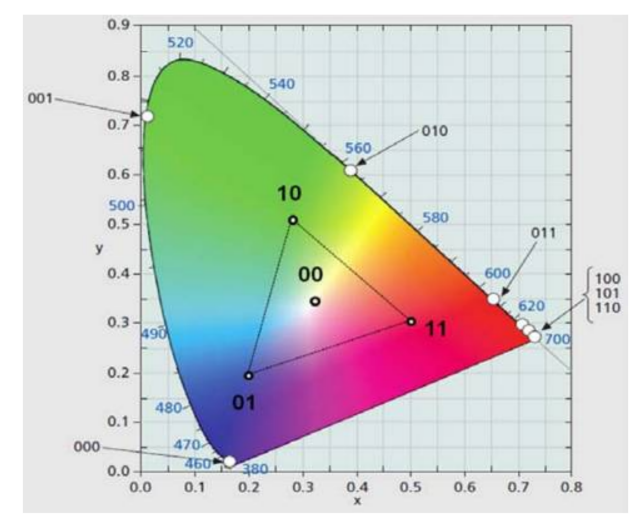

Figure 9. Color mapping constellations for $x, y$ and 4-CSK in CIE 1931 (Color Space proposed by the International Illumination Organization in 1931).

\subsection{Equalization}

Based on the characteristics of the VLC channel, the uneven channel will bring great obstacles to the high-speed transmission of the data. Although OFDM modulation technology can improve the system performance to a certain extent, equalization technology is necessary to further enhance the system capacity. And it can be divided into two kinds: software equalization and hardware equalization. The former mainly involves digital signal processing, while the latter one mainly relates to the circuit design. Equalization applied at the transmitter (pre-equalization) is an efficient way to increase bandwidth as well as enhance the data rate.

\section{(1) Hardware equalization}

According to the previous reports, hardware pre-equalization technology is proved to be an effective way to improve the bandwidth of the VLC system. In 2013, Fujimoto et al. [46] introduced pattern logic (CML) circuits and a simple resistors and capacitors $(\mathrm{RC})$ pre-equalization circuit as the driver circuit of a commercial RGB LED (data transmission using red LED). A data rate of $477 \mathrm{Mb} / \mathrm{s}$ was achieved using a low-cost PIN photodiode and OOK-NRZ modulation scheme, and the bit error rate is less than $10^{-9}$. In 2015, Huang et al. [47] proposed a bridge-T amplitude equalizer, which has excellent linearity and impedance matching performance. A data rate of $2.0 \mathrm{~Gb} / \mathrm{s}$ over $1.5 \mathrm{~m}$ free space was achieved using a commercial phosphorescent white LED with an adaptive bit and a power loading OFDM modulation scheme. 


\section{(2) Software Equalization}

Although hardware equalization can increase the bandwidth of the system to a certain extent, it still suffers from some limitations. But as most of the hardware equalization technologies are based on an analog circuit: (i) analog circuit is susceptible to interference, and its bandwidth is limited, therefore it does not fit for high-speed signal transmission; (ii) The channel of VLC is greatly influenced by the ambient noise, which has higher requirements for the flexibility of the equalizer. However, the analog circuit cannot be debugged and adjusted according to the actual system requirements. Thus, the software equalization providing more accurate and higher flexibility is more attractive [48]. Chi's group introduced a weighted pre-equalization technique for multi-band CAP signals, and combining different post-equalization schemes, they have experimentally demonstrated a $1.35 \mathrm{~Gb} / \mathrm{s}$ [49], a $4.5 \mathrm{~Gb} / \mathrm{s}$ [47], and an $8 \mathrm{~Gb} / \mathrm{s}$ [41] high-speed indoor VLC transmission system, respectively. In 2016, Zhou et al. applied power exponential software pre-equalization in VLC based on a commercial phosphorescent white LED for high speed transmission. A $2.08 \mathrm{~Gb} / \mathrm{s}$ VLC transmission over a $1 \mathrm{~m}$ free-space distance is implemented through experimental demonstration, which is higher than the data rate record created by applying hardware pre-equalization in a phosphorescent white LED based VLC system [48].

\subsection{Blue Filter}

Blue filter is one of the effective ways to improve the data rate and transmission distance of a ps-LED based VLC system $[50,51]$ without increasing the computational complexity at the receiver. And these improvements mainly come from the following two aspects.

(1) Improving the modulation bandwidth of LED. As mentioned above, the modulation bandwidth of ps-LED is limited by the slow relaxation time of the phosphor coating. As shown in Figure 10, the emission spectrum of the phosphor-based white LED consists of a sharp blue peak centered at $456 \mathrm{~nm}$ and a fluorescence peak from 485 to $800 \mathrm{~nm}$. Thus, one of the most effective ways to improve the modulation bandwidth of a phosphor-based LED transmitter is simply removing the slow fluorescence component from the modulated signal with a blue filter [2]. And the study of Grubor et al. shows that by employing a blue filter in front of the receiver, the bandwidth of ps-LED can be increased substantially from 2 up to $20 \mathrm{MHz}$ [52].

(2) Restraining the ambient light. For the silicon PIN or APD photodetector, which is the common receivers of a VLC system, the response spectrum ranges from about 400 to $1050 \mathrm{~nm}$ and has a much higher responsivity in the visible and near-infrared photons than the blue ones (see Figure 10). Therefore, sunlight or light from other artificial lighting, such as fluorescent lamps, computer or television monitors, becomes an inevitable strong ambient light that may greatly lower the SNR and limit the transmission distance of a VLC system [2]. By employing a blue filter, it is expected such ambient light interference might be minimized effectively.

In 2015, the theoretical study of Stepniak et al. [53] indicated that blue filtering had a marginal effect on the performance in ps-LED based VLC for all the investigated modulation formats, including PAM, CAP and DMT, only except for the case of PAM with a decision feedback equalizer (a 1-2 dB higher margin was observed without blue filtering). Wang et al. [2] proposed a high-performance blue filter (see Figure 10) with ultrawide stopband from 500 to $1050 \mathrm{~nm}$, and precisely restraining the phosphorescent component and other ambient light. As shown in Figure 11, the experimental results demonstrated that both the data rate and the transmission distance were greatly improved. Huang et al. [54] has applied this kind of wide stopband blue filter in a high speed VLC system. A data rate of $1.6 \mathrm{~Gb} / \mathrm{s}$ was successfully achieved over a $1 \mathrm{~m}$ free-space transmission with a PIN photodiode using 16QAM-OFDM modulation. 


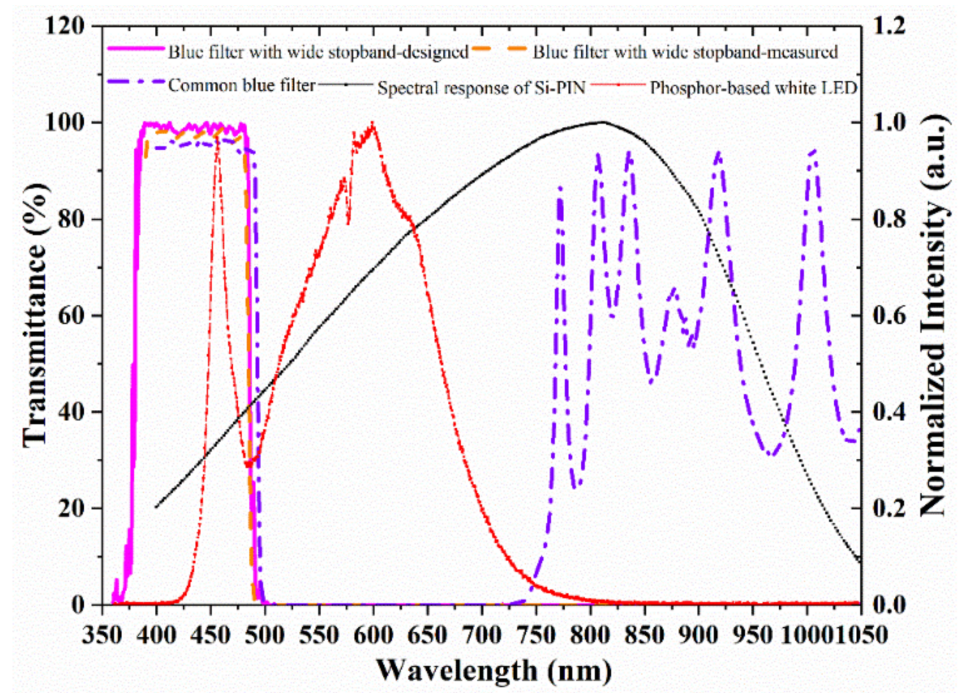

Figure 10. Calculated and measured transmission spectra of the blue filter, as well as the normalized emission spectrum of a phosphor-based white LED and the typical spectral response of a Si-based receiver for reference [2]. Reproduced with permission from [2], IEEE, 2015. (Reprinted from IEEE Wireless Communications, 22, Wang, S. W. etc., A high-performance blue filter for a white-led-based visible light communication system. 61-67, Copyright (2015), with permission from IEEE.)
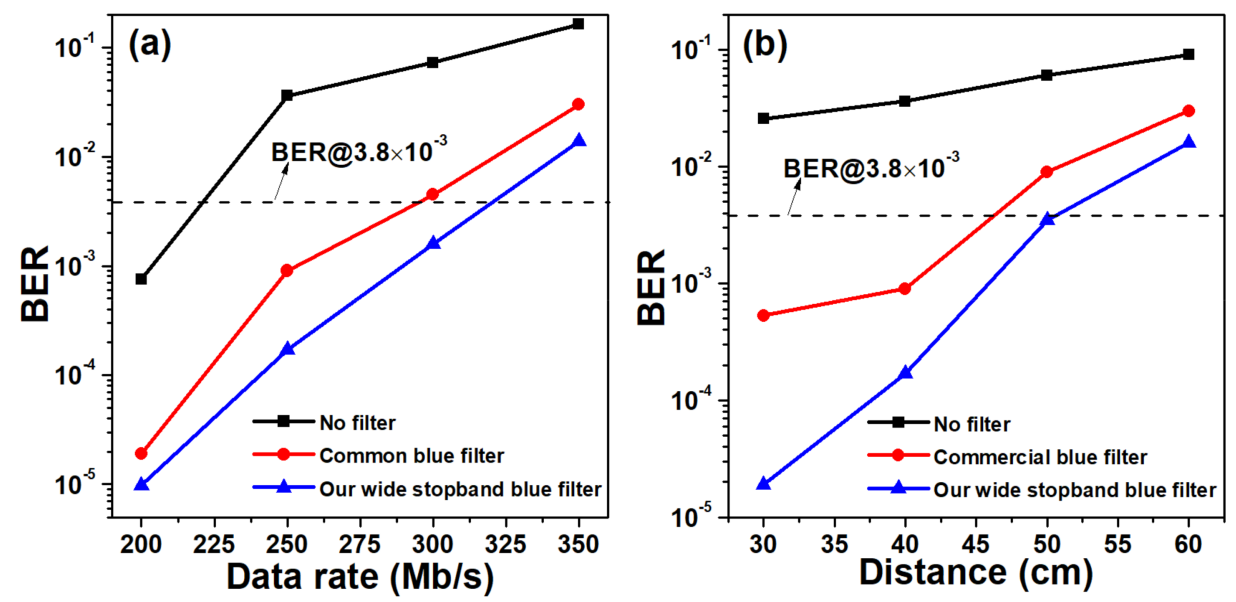

Figure 11. Measured BERs of downlink with no filter, common blue filter and filter versus (a) data rata and (b) distance. Reproduced with permission from [2], IEEE, 2015. (Reprinted from IEEE Wireless Communications, 22, Wang, S.-W. etc., A high-performance blue filter for a white-led-based visible light communication system. 61-67, Copyright (2015), with permission from IEEE.)

\section{State of Art}

In 1999, Pang et al. from Hong Kong University proposed the concept of using fast switched LEDs for communication for the first time [55]. And LED-based VLC began to take shape in the early 2000s in Japan, pioneered by Tanaka et al. [5] at Keio University. Enthusiasm for this research topic has soon spread worldwide and attracted the attention from various institutions and universities. Active research groups include Keio University, Nagoya University, Nakagawa Laboratory, Germany Heinrich Hertz Institute, Siemens Labs, Oxford University, University of Edinburgh, University of Strathclyde, University of Sunnybird, Boston University, University of California, China Taiwan Jiaotong University, Industrial Technology Research Institute, Far East University of Science and Technology, Fudan University, Beijing University of Posts and Telecommunications, Southeast University, Institute of Semiconductors, Chinese Academy of Sciences, Huazhong University of Science and Technology, Jinan 
University, and so on. In November 2003, the Visible Light Communication Consortium (VLCC) was established in Japan to explore different applications of VLC. After Japan, many other large research projects have also been launched, including the Omega Project (2008, European Commission), Smart Lighting Engineering Research Center (2008, USA), Center for Ubiquitous Communication by Light (UC-Light, 2010, USA), Li-Fi Consortium (2011), Center on Optical Wireless Applications (2011, USA) and Canadian Research in VLC (2012). In the recent decade, rapid developments were got, and an IEEE standard (IEEE 802.15.7) was finalized in 2011 [56], enhancing the prospects for commercializing VLC.

Table 1 details the recent efforts by various groups in attaining higher speeds using VLC. Type of transmitters, receivers, modulation, and equalization used in each case are also stated for ease of comparison. As shown in Table 1, several demonstrations have shown that it is possible to construct Gb/s class VLC links. And the type of transmitter is an important factor that affects the data rate. While blue filters, modulation, and equalization technologies can improve the system performance to a certain extent. In 2016, using commercial phosphorescent white LEDs and low-cost PIN photodiodes (PDs), a high-speed VLC transmission at $>1 \mathrm{~Gb} / \mathrm{s}$ over a free-space link of $0.6 \mathrm{~m}$ in a $2 \times 2$ multiple-input multiple-output (MIMO) visible light communication (VLC) system [57] was achieved. And a $2.08 \mathrm{~Gb} / \mathrm{s}$ transmission data rate over $1 \mathrm{~m}$ free-space transmission distance is achieved by further applying adaptive bit and power loading OFDM [48]. Multi-chips can greatly improve the bandwidth of LED. Ref [58] presented the proof-of-concept of the RGB $2 \times 2$ MIMO VLC system with a data rate of $6.36 \mathrm{~Gb} / \mathrm{s}$ over a free-space link of $1 \mathrm{~m}$ in a RGB LED-based $2 \times 2$ polarization-multiplexing MIMO VLC system. And an aggregate data rate of $8 \mathrm{~Gb} / \mathrm{s}$ is successfully achieved over $1 \mathrm{~m}$ indoor free space transmission with RYGB LEDs by the hybrid equalizer [41]. A novel violet micro-LED array with two sets of inner and outer pixels is reported in Ref [28]. The electrical-to-optical bandwidth is up to $655 \mathrm{MHz}$ at an optical output power of $2.3 \mathrm{~mW}$. And a data transmission rate of $7.36 \mathrm{~Gb} / \mathrm{s}$ is achieved in an adaptive bit and energy loading OFDM-based VLC system using a single pixel of the proposed violet micro-LED. In 2017, Huang et al. realized a $17.6 \mathrm{~Gb} / \mathrm{s}$ transmission in a GaN LD based VLC system with impedance-matched transmission-line circuit board and a UFMC additive 16-QAM OFDM [30]. And this is the highest data rate ever obtained in high-speed VLC systems till now. Besides the common transmitters, VLC systems based on other transmitters, such as the combinations of LD and phosphors, $\mu$-LED and polymer color converter as well as RC-LED and $\mu$-LEDs also can achieve $\mathrm{Gb} / \mathrm{s}$ class transmission data rates with proper system setups.

Table 1. Survey of practical demonstrations of high-speed VLC systems.

\begin{tabular}{|c|c|c|c|c|c|c|c|}
\hline Year & Transmitter & Receiver & Modulation & Data Rate & Distance & Comments & Ref \\
\hline 2017 & Blue LD & $\begin{array}{c}\text { Ultrafast } \\
\text { photodiode(UPD) }\end{array}$ & $\begin{array}{l}\text { UFMC additive } \\
\text { 16-QAM OFDM }\end{array}$ & $17.6 \mathrm{~Gb} / \mathrm{s}$ & $16 \mathrm{~m}$ & / & {$[30]$} \\
\hline 2017 & RYGB LDs & $\begin{array}{c}\text { Imaging Diversity } \\
\text { Receiver }\end{array}$ & OOK & $10 \mathrm{~Gb} / \mathrm{s}$ & / & / & [59] \\
\hline 2017 & $\begin{array}{l}\text { NUV LD+ RGB } \\
\text { phosphors }\end{array}$ & APD & OOK-NRZ & $1.25 \mathrm{~Gb} / \mathrm{s}$ & $15 \mathrm{~cm}$ & / & {$[60]$} \\
\hline 2017 & $\mu$-LED & PIN & OFDM & $7.91 \mathrm{~Gb} / \mathrm{s}$ & I & I & [28] \\
\hline 2017 & $\mu$-LED & APD & PAM(spatial) & $7 \mathrm{~Gb} / \mathrm{s}$ & $0.5 \mathrm{~m}$ & $\begin{array}{l}9 \times 9 \text { MIMO system } \\
\text { Post-equalization }\end{array}$ & [61] \\
\hline 2017 & RGB LED & PIN & $\begin{array}{l}\text { OFDM(adaptive bit } \\
\text { loading) }\end{array}$ & $6.36 \mathrm{~Gb} / \mathrm{s}$ & $1 \mathrm{~m}$ & $2 \times 2$ MIMO system & [58] \\
\hline 2017 & Red LED & silicon PN & OOK & $600 \mathrm{Mb} / \mathrm{s}$ & $6 \mathrm{~m}$ & $\begin{array}{l}2 \times 2 \text { imaging MIMO system } \\
\text { Pre- and Post-equalization }\end{array}$ & {$[62]$} \\
\hline 2016 & LD & I & OOK & $1 \mathrm{~Gb} / \mathrm{s}$ & 1 & 1 & [63] \\
\hline 2016 & $\begin{array}{l}\text { Red RC-LED and blue } \\
\text { and green } \mu \text {-LEDs }\end{array}$ & PIN & OFDM(WDM) & $10 \mathrm{~Gb} / \mathrm{s}$ & $1.5 \mathrm{~m}$ & / & [64] \\
\hline 2016 & $\mu$-LED & I & DCO-OFDM & $5 \mathrm{~Gb} / \mathrm{s}$ & & I & [29] \\
\hline 2016 & $\mu$-LED & I & PAM & $3.5 \mathrm{~Gb} / \mathrm{s}$ & & Post-equalization & [29] \\
\hline 2016 & $\mu$-LED & APD & PAM & $2 \mathrm{~Gb} / \mathrm{s}$ & $0.6 \mathrm{~m}$ & Pre-equalization & [65] \\
\hline 2016 & RGB-LED & APD & QAM-OFDM & $1 \mathrm{~Gb} / \mathrm{s}$ & $100 \mathrm{~m}$ & I & [66] \\
\hline 2016 & ps-LED & PIN & $\begin{array}{l}\text { OFDM (adaptive bit } \\
\text { and power loading) }\end{array}$ & $2.08 \mathrm{~Gb} / \mathrm{s}$ & $1 \mathrm{~m}$ & Pre-equalization & [48] \\
\hline
\end{tabular}


Table 1. Cont.

\begin{tabular}{|c|c|c|c|c|c|c|c|}
\hline Year & Transmitter & Receiver & Modulation & Data Rate & Distance & Comments & Ref. \\
\hline 2016 & ps-LED & PIN & OFDM (bit-loading) & $1 \mathrm{~Gb} / \mathrm{s}$ & $0.6 \mathrm{~m}$ & $\begin{array}{l}2 \times 2 \text { MIMO System } \\
\text { Pre-equalization }\end{array}$ & [57] \\
\hline 2015 & RGB LDs & PIN & OFDM(WDM) & $14 \mathrm{~Gb} / \mathrm{s}$ & $2.8 \mathrm{~m}$ & / & [67] \\
\hline 2015 & RGB LDs & APD & OFDM(WDM) & $4.4 \mathrm{~Gb} / \mathrm{s}$ & $0.2 \mathrm{~m}$ & 1 & [68] \\
\hline 2015 & Blue LDs & APD & OFDM & $9 \mathrm{~Gb} / \mathrm{s}$ & $5 \mathrm{~m}$ & 1 & [69] \\
\hline 2015 & Blue LD + phosphor & / & $\begin{array}{l}\text { OFDM (adaptive bit } \\
\text { and power loading) }\end{array}$ & $6.52 \mathrm{~Gb} / \mathrm{s}$ & $0.35 \mathrm{~m}$ & / & [70] \\
\hline 2015 & Blue LD + phosphor & APD & OFDM & $5.2 \mathrm{~Gb} / \mathrm{s}$ & $0.6 \mathrm{~m}$ & I & [71] \\
\hline 2015 & Blue LD + phosphor & APD & OFDM & $4 \mathrm{~Gb} / \mathrm{s}$ & $0.5 \mathrm{~m}$ & 1 & [72] \\
\hline 2015 & Blue LD + phosphor & APD & OOK & $4 \mathrm{~Gb} / \mathrm{s}$ & 1 & 1 & [73] \\
\hline 2015 & $\begin{array}{l}\mu \text {-LED + polymer } \\
\text { color converter }\end{array}$ & APD & $\begin{array}{l}\text { DCO-OFDM } \\
\text { (WDM) }\end{array}$ & $2.3 \mathrm{~Gb} / \mathrm{s}$ & / & / & [74] \\
\hline 2015 & RYGB LED & PIN & CAP(WDM) & $8 \mathrm{~Gb} / \mathrm{s}$ & $1 \mathrm{~m}$ & Pre- and Post-equalization & [41] \\
\hline 2015 & RYGB LED & $\mathrm{APD}$ & OFDM(WDM) & $5.6 \mathrm{~Gb} / \mathrm{s}$ & $4 \mathrm{~m}$ & & [75] \\
\hline 2015 & RGB LED & PIN & CAP & $4.5 \mathrm{~Gb} / \mathrm{s}$ & $2 \mathrm{~m}$ & Pre-equalization & [47] \\
\hline 2015 & RGB LED & APD & QAM-OFDM & $750 \mathrm{Mb} / \mathrm{s}$ & / & Pre-equalization & [47] \\
\hline 2015 & LED & PIN & OFDM(Spatial) & $1.4 \mathrm{~Gb} / \mathrm{s}$ & $2.5 \mathrm{~m}$ & $2 \times 2$ imaging MIMO-VLC system & [76] \\
\hline 2015 & ps-LED & APD & $\begin{array}{l}\text { OFDM(adaptive bit } \\
\text { and power loading) }\end{array}$ & $2 \mathrm{~Gb} / \mathrm{s}$ & $1.5 \mathrm{~m}$ & Pre-equalization & [36] \\
\hline 2015 & ps-LED & PIN & OFDM & $1.6 \mathrm{~Gb} / \mathrm{s}$ & $1 \mathrm{~m}$ & $\begin{array}{l}\text { Pre-equalization } \\
\text { Blue filter }\end{array}$ & [54] \\
\hline 2015 & ps-LED & APD & QAM-OFDM & $1.4 \mathrm{~Gb} / \mathrm{s}$ & $0.8 \mathrm{~m}$ & Pre-equalization & [77] \\
\hline 2015 & ps-LED & APD & OFDM(Spatial) & $1.3 \mathrm{~Gb} / \mathrm{s}$ & $0.4 \mathrm{~m}$ & I & [78] \\
\hline 2015 & ps-LED & PIN & PAM & $1.1 \mathrm{~Gb} / \mathrm{s}$ & I & Post-equalization & [79] \\
\hline 2015 & ps-LED & PIN & QAM-OFDM & $682 \mathrm{Mb} / \mathrm{s}$ & $1 \mathrm{~m}$ & Pre-equalization & [80] \\
\hline 2014 & $\mu$-LED & PD & $\begin{array}{l}\text { OFDM(adaptive bit } \\
\text { and power loading) }\end{array}$ & $3 \mathrm{~Gb} / \mathrm{s}$ & $5 \mathrm{~cm}$ & / & [81] \\
\hline 2014 & $\begin{array}{l}\mu \text {-LED + polymer } \\
\text { color converter(white) }\end{array}$ & APD & OFDM & $1.68 \mathrm{~Gb} / \mathrm{s}$ & $3 \mathrm{~cm}$ & / & [82] \\
\hline 2014 & RGB LED & APD & QAM (Wavelength) & $4.22 \mathrm{~Gb} / \mathrm{s}$ & 1 & 1 & [83] \\
\hline 2014 & RGB LED & APD & $\mathrm{CAP}(\mathrm{WDM})$ & $1.35 \mathrm{~Gb} / \mathrm{s}$ & $0.3 \mathrm{~m}$ & Pre- and Post-equalization & [49] \\
\hline 2014 & RGB-LED & APD & $\begin{array}{c}\text { 16-QAM } \\
\text { (Polarisation) }\end{array}$ & $1 \mathrm{~Gb} / \mathrm{s}$ & / & Post-equalization & [84] \\
\hline 2014 & Blue-LED & APD & 4-QAM(Spatial) & $500 \mathrm{Mb} / \mathrm{s}$ & $0.3 \mathrm{~m}$ & $\begin{array}{c}2 \times 2 \text { non-imaging MIMO System } \\
\text { Post-equalization }\end{array}$ & [85] \\
\hline 2014 & ps-LED & PIN & OOK-NRZ & $550 \mathrm{Mb} / \mathrm{s}$ & $0.6 \mathrm{~m}$ & Pre- and Post-equalization & [86] \\
\hline 2014 & ps-LED & PIN & OOK-NRZ & $340 \mathrm{Mb} / \mathrm{s}$ & $0.43 \mathrm{~m}$ & $\begin{array}{l}\text { Post-equalization } \\
\text { Blue filter }\end{array}$ & [87] \\
\hline 2014 & ps-LED & PIN & OOK-NRZ (Spatial) & $50 \mathrm{Mb} / \mathrm{s}$ & $2 \mathrm{~m}$ & $\begin{array}{c}\text { Pre-equalization } \\
4 \times 4 \text { Non-imaging MIMO system }\end{array}$ & [88] \\
\hline
\end{tabular}

Note: / represents not mentioned in the article.

\section{Limitations}

In the gradually mature and practical path of VLC, there are still some issues that need to be addressed by in-depth study in future researches:

(1) Thermal management of high power LEDs. The junction temperature of the LED may be changed with the variation of self-heating, drive current, ambient temperature and so on. Thus, in the VLC system, especially the ones run at high drive currents or where hundreds of LEDs are integrated, the high junction temperature may affect the dominant wavelength [89], spectral width [90], the internal efficiency, and finally leads to the degradation of signal power and reduces the SNR [7]. In addition, when the LEDs are suffered from long-term excessive heat, both the stability and the lifetime of the LED are drastically reduced [91]. Therefore, how to effectively monitor and reduce the LED junction temperature is a key issue of effective VLC implementation.

(2) Bi-Directional Transmission. Basically, VLC is a kind of broadcast transmission, thus, how to provide an uplink path to realize a bi-directional transmission is challenging. To achieve the uplink path, several approaches have been proposed. For example, Komine et al. [92] proposed a corner cube modulator for the uplink VLC path. The modulator is basically a retro-reflecting modulator, 
i.e., the reflected LED light by the corner cube reflector acts as the media for uplink communication. Hou et al. [93] described an uplink using RF. While in some RF restricted areas, this approach is not feasible. Liu et al. [94] experimentally demonstrated a bi-directional transmission link using a LED-based VLC for both downlink and uplink paths. And a Time-division-duplex (TDD) was applied to eliminate the reflection interference. Results show that a $2 \mathrm{~m}$ bi-directional transmission with $\mathrm{BER}<10^{-5}$ is achieved.

(3) Lights Off Mode. Since the VLC aims to offer simultaneous illumination and high-speed data transmission, how to transmit data when the lights are turned off is a significant problem to be solved, especially for the indoor VLC applications. Utilizing the feature of limited perception to light intensity of human eyes, some data transmission may be realized by making the emitted light perceptibly off. Borogovac et al. [95] suggest the perceptibly of off light intensity is sufficient to maintain data rates of several $\mathrm{Mb} / \mathrm{s}$. While in order to obtain a high data transmission in lights off mode, a hybrid scheme of VLC and RF or IR is necessary. And how to achieve such a hybrid scheme with low complexity and cost is an important issue to deal with.

\section{Conclusions}

Owing to the various inherent advantages, such as spectral and bandwidth relief, no healthy concern, high security, low cost and low interference with RF waves, VLC have emerged as one of the most energy efficient and promising wireless communication approaches. How to achieve a high-speed data transmission is a key problem to be solved in the VLC system. In this review, the possible solutions to improve the data rate, including novel transmitter architecture, advanced modulation and equalization technology and blue filter were elaborately discussed elaborately. And recent progresses show that the type of transmitter is an important factor that affects the data rate. Modulation and equalization technologies can improve the system performance to a certain extent. Blue filter has a marginal effect for the ps-LED based VLC system, and can improve its performance without increasing the computational complexity at the receiver. Till now, the highest data rate achieved in a commercial phosphorescent white LED-based VLC system is $2.08 \mathrm{~Gb} / \mathrm{s}$ over a $1 \mathrm{~m}$ free-space transmission distance. And the data rate is up to $17.6 \mathrm{~Gb} / \mathrm{s}$ transmission in a GaN LD based VLC system with impedance-matched transmission-line circuit board and UFMC additive 16-QAM OFDM. In the gradually mature and practical path, there are still some issues that need to be addressed by in-depth study in future researches, such as LED thermal management, bi-directional transmission, data transmission in lights off mode and so on. Despite this, with the development of new devices and related technologies, VLC is foreseen to be readily implemented into general lighting infrastructures to achieve various exciting and beneficial applications.

Acknowledgments: This work was partially supported by the Shanghai Science and Technology Foundations (15DZ2282100, 16DZ2290600, 18590712600), Youth Innovation Promotion Association CAS and New Teachers Research Funding Project of Northwestern Polytechnical University (3102017OQD076).

Author Contributions: All authors contributed to the research work. Wei Lu proposed the frame of the paper, Ruonan Ji wrote the paper, Qingquan Liu contributed to the figures and table, Shaowei Wang revised the paper.

Conflicts of Interest: The authors declare no conflict of interest.

\section{References}

1. Jackson, D.K.; Buffaloe, T.K.; Leeb, S.B. Fiat lux: A fluorescent lamp digital transceiver. IEEE Trans. Ind. Appl. 1998, 34, 625-630. [CrossRef]

2. Wang, S.-W.; Chen, F.; Liang, L.; He, S.; Wang, Y.; Chen, X.; Lu, W. A high-performance blue filter for a white-led-based visible light communication system. IEEE Wirel. Commun. 2015, 22, 61-67. [CrossRef]

3. Parikh, H.; Chokshi, J.; Gala, N. Wirelessly transmitting a grayscale image using visible light. Int. J. Comput. Appl. 2012, 58, 1-6. [CrossRef] 
4. Classen, J.; Chen, J.; Steinmetzer, D.; Hollick, M.; Knightly, E. The spy next door: Eavesdropping on high throughput visible light communications. In Proceedings of the International Workshop on Visible Light Communications Systems, Paris, France, 11 September 2015; pp. 9-14.

5. Zhao, S.; Xu, J.; Trescases, O. A dimmable led driver for visible light communication (VLC) based on llc resonant dc-dc converter operating in burst mode. In Proceedings of the Applied Power Electronics Conference and Exposition, Long Beach, CA, USA, 17-21 March 2013; pp. 2144-2150.

6. Ma, H.; Lampe, L.; Hranilovic, S. Integration of indoor visible light and power line communication systems. In Proceedings of the IEEE International Symposium on Power Line Communications and ITS Applications, Johannesburg, South Africa, 24-27 March 2013; pp. 291-296.

7. Karunatilaka, D.; Zafar, F.; Kalavally, V.; Parthiban, R. LED based indoor visible light communications: State of the art. IEEE Commun. Surv. Tutor. 2015, 17, 1649-1678. [CrossRef]

8. Chow, C.W.; Yeh, C.H.; Liu, Y.F.; Liu, Y. Improved modulation speed of LED visible light communication system integrated to main electricity network. Electron. Lett. 2011, 47, 867-868. [CrossRef]

9. Zhang, M.; Zhang, Z. Fractionally spaced equalization in visible light communication. In Proceedings of the IEEE Wireless Communications and Networking Conference (WCNC), Shanghai, China, 7-10 April 2013.

10. U.S. Department of Energy. Solid-State Lighting Research and Development: Multi-Year Program Plan; U.S. Department of Energy: Washington, DC, USA, 2012.

11. Li-Fi Revolution: Internet Connections Using Light Bulbs Are 250 Times Faster than Broadband. Available online: http:/ / www.independent.co.uk/news/science/li-fi-revolution-internet-connections-usinglight-bulbs-are-250-times-faster-than-broadband-8909320.html (accessed on 1 January 2018).

12. Chew, I.; Karunatilaka, D.; Tan, C.P.; Kalavally, V. Smart lighting: The way forward? Reviewing the past to shape the future. Energy Build. 2017, 149, 180-191. [CrossRef]

13. Rust, I.C.; Asada, H.H. A dual-use visible light approach to integrated communication and localization of underwater robots with application to non-destructive nuclear reactor inspection. In Proceedings of the IEEE International Conference on Robotics and Automation, Saint Paul, MN, USA, 14-18 May 2012; pp. 2445-2450.

14. Doniec, M.; Vasilescu, I.; Chitre, M.; Detweiler, C.; Hoffmann-Kuhnt, M.; Rus, D. Aquaoptical: A lightweight device for high-rate long-range underwater point-to-point communication. Mar. Technol. Soc. J. 2010, 44, 1-6. [CrossRef]

15. Malta, L.; Miyajima, C.; Takeda, K. A study of driver behavior under potential threats in vehicle traffic. IEEE Trans. Intell. Transp. Syst. 2009, 10, 201-210. [CrossRef]

16. CAMP vehicle safety communications consortium. References. In Vehicle Safety Communications Project Task 3 Final Report: Identify Intelligent Vehicle Safety Applications Enabled by DSRC; Department of Transportation, National Highway Traffic Safety Administration: Washington, DC, USA, 2005; pp. 67-138.

17. Pathak, P.H.; Feng, X.; Hu, P.; Mohapatra, P. Visible light communication, networking, and sensing: A survey, potential and challenges. IEEE Commun. Surv. Tutor. 2015, 17, 2047-2077. [CrossRef]

18. Komine, T.; Lee, J.H.; Haruyama, S.; Nakagawa, M. Adaptive equalization system for visible light wireless communication utilizing multiple white LED lighting equipment. IEEE Trans. Wirel. Commun. 2009, 8, 2892-2900. [CrossRef]

19. Oh, H.S.; Hue Joo, J.; Lee, J.H.; Hyeob Baek, J.; Seo, J.W.; Kwak, J.S. Structural optimization of high-power algainp resonant cavity light-emitting diodes for visible light communications. Jpn. J. Appl. Phys. 2008, 47, 6214-6216. [CrossRef]

20. Shi, J.W.; Sheu, J.K.; Chen, C.H.; Lin, G.R.; Lai, W.C. High-speed GaN-based green light-emitting diodes with partially N-doped active layers and current-confined apertures. IEEE Electron Device Lett. 2008, 29, 158-160. [CrossRef]

21. IEEE 802.15 WPAN Task Group 7 (TG7) Visible Light Communication. Available online: http://www. ieee802.org/15/pub/TG7.html (accessed on 1 January 2018).

22. Shaw, A.J.; Bradley, A.L.; Donegan, J.F.; Lunney, J.G. Gan resonant cavity light-emitting diodes for plastic optical fiber applications. IEEE Photon. Technol. Lett. 2004, 16, 2006-2008. [CrossRef]

23. Dorsaz, J.; Carlin, J.F.; Zellweger, C.M.; Gradecak, S.; Ilegems, M. InGaN/GaN resonant-cavity LED including an AlInN/GaN bragg mirror. Phys. Status Solidi 2004, 201, 2675-2678. [CrossRef] 
24. Kelly, A.E.; Mckendry, J.J.D.; Zhang, S.; Massoubre, D.; Rae, B.R.; Green, R.P.; Henderson, R.K.; Dawson, M.D. High-speed GaN micro-LED arrays for data communications. In Proceedings of the International Conference on Transparent Optical Networks, Coventry, UK, 2-5 July 2012; pp. 1-5.

25. Zhang, S.; Watson, S.; Mckendry, J.J.D.; Massoubre, D.; Cogman, A.; Gu, E.; Henderson, R.K.; Kelly, A.E.; Dawson, M.D. 1.5 Gbit/s multi-channel visible light communications using CMOS-controlled GaN-based LEDs. J. Lightwave Technol. 2013, 31, 1211-1216. [CrossRef]

26. Mckendry, J.J.D.; Green, R.P.; Kelly, A.E.; Gong, Z.; Guilhabert, B.; Massoubre, D.; Gu, E.; Dawson, M.D. High-speed visible light communications using individual pixels in a micro light-emitting diode array. IEEE Photonics Technol. Lett. 2010, 22, 1346-1348. [CrossRef]

27. Mckendry, J.J.D.; Massoubre, D.; Zhang, S.; Rae, B.R.; Green, R.P.; Gu, E.; Henderson, R.K.; Kelly, A.E.; Dawson, M.D. Visible-light communications using a CMOS-controlled micro-light- emitting-diode array. J. Lightwave Technol. 2011, 30, 61-67. [CrossRef]

28. Islim, M.; Ferreira, R.; He, X.; Xie, E.; Videv, S.; Viola, S.; Watson, S.; Bamiedakis, N.; Penty, R.; White, I. Towards $10 \mathrm{~Gb} / \mathrm{s}$ OFDM-based visible light communication using a GaN violet micro-LED. Photonics Res. 2017, 5, A35-A43. [CrossRef]

29. Ferreira, R.X.G.; Xie, E.; Mckendry, J.J.D.; Rajbhandari, S.; Chun, H.; Faulkner, G.; Watson, S.; Kelly, A.E.; Gu, E.; Penty, R.V. High bandwidth GaN-based micro-LEDs for multi-Gb/s visible light communications. IEEE Photonics Technol. Lett. 2016, 28, 2023-2026. [CrossRef]

30. Tsai, C.T.; Lin, G.R.; Kao, H.Y.; Wang, H.Y.; Shih, T.T.; Chi, Y.C.; Huang, Y.F. 17.6-gbps universal filtered multi-carrier encoding of GaN blue ld for visible light communication. In Proceedings of the Conference on Lasers and Electro-Optics (CLEO), San Jose, CA, USA, 14-19 May 2017.

31. Neumann, A.; Wierer, J.J.; Davis, W.; Ohno, Y.; Brueck, S.R.; Tsao, J.Y. Four-color laser white illuminant demonstrating high color-rendering quality. Opt. Express 2011, 19 (Suppl. 4), A982-A990. [CrossRef] [PubMed]

32. Zafar, F.; Bakaul, M.; Parthiban, R. Laser-diode-based visible light communication: Toward gigabit class communication. IEEE Commun. Mag. 2017, 55, 144-151. [CrossRef]

33. Armstrong, J.; Lowery, A.J. Power efficient optical OFDM. Electron. Lett. 2006, 42, 370-372. [CrossRef]

34. Armstrong, J.; Schmidt, B. Comparison of asymmetrically clipped optical OFDM and DC-biased optical OFDM in AWGN. IEEE Commun. Lett. 2008, 12, 343-345. [CrossRef]

35. Dissanayake, S.D.; Armstrong, J. Comparison of ACO-OFDM, DCO-OFDM and ADO-OFDM in IM/DD systems. J. Lightwave Technol. 2013, 31, 1063-1072. [CrossRef]

36. Huang, X.; Chen, S.; Wang, Z.; Shi, J.; Wang, Y.; Xiao, J.; Chi, N. 2.0-Gb/s visible light link based on adaptive bit allocation OFDM of a single phosphorescent white LED. IEEE Photonics J. 2015, 7, 1-8. [CrossRef]

37. Mesleh, R.; Elgala, H.; Haas, H. Performance analysis of indoor OFDM optical wireless communication systems. In Proceedings of the Wireless Communications and Networking Conference, Las Vegas, NV, USA, 14-17 January 2012; pp. 1005-1010.

38. Bao, Y.; Li, Z.; Li, J.; Feng, X.; Guan, B.O.; Li, G. Nonlinearity mitigation for high-speed optical OFDM transmitters using digital pre-distortion. Opt. Express 2013, 21, 7354-7361. [CrossRef] [PubMed]

39. Elgala, H.; Mesleh, R.; Haas, H. Non-linearity effects predistortion in optical OFDM wireless transmission using LEDs. Int. J. Ultra Wideband Commun. Syst. 2009, 1, 143-150. [CrossRef]

40. Wang, Y.; Tao, L.; Huang, X.; Shi, J.; Chi, N. Enhanced performance of a high-speed WDM CAP64 VLC system employing volterra series-based nonlinear equalizer. IEEE Photonics J. 2015, 7, 1-7. [CrossRef]

41. Wang, Y.; Tao, L.; Huang, X.; Shi, J.; Chi, N. 8-Gb/s RGBY LED-based wdm VLC system employing high-order CAP modulation and hybrid post equalizer. IEEE Photonics J. 2015, 7, 1-7.

42. Monroy, I.T.; Turkiewicz, J.; Siuzdak, J.; Jensen, J.B.; Wieckowski, M.; Rodes, R.; Pham, T.T. Carrierless amplitude phase modulation of vcsel with $4 \mathrm{bit} / \mathrm{s} / \mathrm{Hz}$ spectral efficiency for use in wdm-pon. Opt. Express 2011, 19, 26551-26556.

43. Wu, F.M.; Lin, C.T.; Wei, C.C.; Chen, C.W.; Chen, Z.Y.; Huang, H.T.; Chi, S. Performance comparison of OFDM signal and CAP signal over high capacity RGB-LED-based wdm visible light communication. IEEE Photonics J. 2013, 5, 7901507. [CrossRef]

44. Monteiro, E.; Hranilovic, S. Design and implementation of color-shift keying for visible light communications. J. Lightwave Technol. 2014, 32, 2053-2060. [CrossRef] 
45. Singh, R.; O'Farrell, T.; David, J.P.R. An enhanced color shift keying modulation scheme for high-speed wireless visible light communications. J. Lightwave Technol. 2014, 32, 2582-2592. [CrossRef]

46. Fujimoto, N.; Mochizuki, H. 477 Mbit/s visible light transmission based on OOK-NRZ modulation using a single commercially available visible LED and a practical LED driver with a pre-emphasis circuit. In Proceedings of the Optical Fiber Communication Conference and Exposition and the National Fiber Optic Engineers Conference, Anaheim, CA, USA, 17-21 March 2013; pp. 1-3.

47. Huang, X.; Shi, J.; Li, J.; Wang, Y.; Wang, Y.; Chi, N. 750Mbit/s visible light communications employing 64QAM-OFDM based on amplitude equalization circuit. In Proceedings of the Optical Fiber Communications Conference and Exhibition, Los Angeles, CA, USA, 22-26 March 2015; pp. 1-3.

48. Zhou, Y.; Liang, S.; Chen, S.; Huang, X.; Chi, N. 2.08 Gbit/s visible light communication utilizing power exponential pre-equalization. In Proceedings of the Wireless and Optical Communication Conference, Chengdu, China, 21-23 May 2016; pp. 1-3.

49. Wang, Y.; Tao, L.; Wang, Y.; Chi, N. High speed WDM VLC system based on multi-band CAP64 with weighted pre-equalization and modified CMMA based post-equalization. IEEE Commun. Lett. 2014, 18, 1719-1722. [CrossRef]

50. Hao, L.M.; O’Brien, D.; Faulkner, G.; Zeng, L. 80 Mbit/s visible light communications using pre-equalized white LED. In Proceedings of the European Conference on Optical Communication, Brussels, Belgium, 21-25 September 2008; pp. 1-2.

51. Minh, H.L.; O’Brien, D.; Faulkner, G.; Zeng, L.; Lee, K.; Jung, D.; Oh, Y.J.; Won, E.T. 100-Mb/s NRZ visible light communications using a postequalized white LED. IEEE Photonics Technol. Lett. 2009, 21, 1063-1065. [CrossRef]

52. Grubor, J.; Walewski, J.W.; Langer, K.D.; Randel, S. Broadband information broadcasting using LED-based interior lighting. J. Lightwave Technol. 2009, 26, 3883-3892. [CrossRef]

53. Stepniak, G.; Schüppert, M.; Bunge, C.A. Advanced modulation formats in phosphorous LED VLC links and the impact of blue filtering. J. Lightwave Technol. 2015, 33, 4413-4423. [CrossRef]

54. Shi, J.; Chi, N.; Huang, X.; Wang, Y.; Wang, Z. 1.6 Gbit/s phosphorescent white LED based VLC transmission using a cascaded pre-equalization circuit and a differential outputs PIN receiver. Opt. Express 2015, 23, 22034-22042.

55. Pang, G.; Ho, K.L.; Kwan, T.; Yang, E. Visible light communication for audio systems. IEEE Trans. Consum. Electron. 1999, 45, 1112-1118. [CrossRef]

56. IEEE 802.15.7-2011. IEEE Standard for Local and Metropolitan Area Networks_Part 15.7: Short-Range Wireless Optical Communication Using Visible Light; IEEE: New York, NY, USA, 2011; pp. 301-309.

57. Lu, I.C.; Liu, Y.L.; Lai, C.H. High-speed $2 \times 2$ MIMO-OFDM visible light communication employing phosphorescent LED. In Proceedings of the Eighth International Conference on Ubiquitous and Future Networks, Vienna, Austria, 5-8 July 2016; pp. 222-224.

58. Lu, I.C.; Lai, C.H.; Yeh, C.H.; Chen, J. 6.36 Gbit/s RGB LED-based WDM MIMO visible light communication system employing OFDM modulation. In Proceedings of the Optical Fiber Communications Conference and Exhibition, Los Angeles, CA, USA, 19-23 March 2017.

59. Younus, S.; Elmirghani, J. WDM for high-speed indoor visible light communication system. In Proceedings of the 19th International Conference on Transparent Optical Networks (ICTON), Girona, Spain, 2-6 July 2017.

60. Lee, C.; Shen, C.; Cozzan, C.; Farrell, R.M.; Speck, J.S.; Nakamura, S.; Ooi, B.S.; Denbaars, S.P. Gigabit-per-second white light-based visible light communication using near-ultraviolet laser diode and red-, green-, and blue-emitting phosphors. Opt. Express 2017, 25, 17480-17487. [CrossRef] [PubMed]

61. Rajbhandari, S.; Jalajakumari, A.V.N.; Chun, H.; Faulkner, G.; Cameron, K.; Tsonev, D.; Haas, H.; Xie, E.; Mckendry, J.J.D.; Herrnsdorf, J.J.D. A multi-gigabit/sec integrated multiple input multiple output VLC demonstrator. J. Lightwave Technol. 2017, 35, 4358-4365. [CrossRef]

62. Fahs, B.; Senneca, M.J.; Chellis, J.; Mazzara, B.; Ray, S.; Ghasemi, J.; Miao, Y.; Zarkesh-Ha, P.; Koomson, V.J.; Hella, M.M. A meter-scale 600-mb/s $2 \times 2$ imaging MIMO OOK VLC link using commercial LEDs and si p-n photodiode array. In Proceedings of the Wireless and Optical Communication Conference, Newark, NJ, USA, 7-8 April 2017; pp. 1-6.

63. Shen, C.; Ng, T.K.; Leonard, J.T.; Pourhashemi, A.; Oubei, H.M.; Alias, M.S.; Nakamura, S.; Denbaars, S.P.; Speck, J.S.; Alyamani, A.Y. High-modulation-efficiency, integrated waveguide modulator-laser diode at $448 \mathrm{~nm}$. ACS Photonics 2016, 3, 262-268. [CrossRef] 
64. Chun, H.; Rajbhandari, S.; Faulkner, G.; Tsonev, D.; Xie, E.; Mckendry, J.J.D.; Gu, E.; Dawson, M.D.; O'Brien, D.C.; Haas, H. LED based wavelength division multiplexed $10 \mathrm{~Gb} / \mathrm{s}$ visible light communications. J. Lightwave Technol. 2016, 34, 3047-3052. [CrossRef]

65. Gu, E.; Xie, E.; White, I.H.; Mckendry, J.J.D.; Dawson, M.D.; Bamiedakis, N.; Ferreira, R.; Penty, R.V.; Guo, X.; Li, X. Wireless visible light communications employing feed-forward pre-equalization and PAM-4 modulation. J. Lightwave Technol. 2016, 34, 2049-2055.

66. Wang, Y.; Chi, N. Long-range high-speed visible light communication system over 100-m outdoor transmission utilizing receiver diversity technology. Opt. Eng. 2016, 55. [CrossRef]

67. Tsonev, D.; Videv, S.; Haas, H. Towards a $100 \mathrm{~Gb} / \mathrm{s}$ visible light wireless access network. Opt. Express 2015, 23, 1627-1637. [CrossRef] [PubMed]

68. Janjua, B.; Oubei, H.M.; Durán Retamal, J.R.; Ng, T.K.; Tsai, C.T.; Wang, H.Y.; Chi, Y.C.; Kuo, H.C.; Lin, G.R.; He, J.H. Going beyond 4 Gbps data rate by employing RGB laser diodes for visible light communication. Opt. Express 2015, 23, 18746-18753. [CrossRef] [PubMed]

69. Chi, Y.C.; Hsieh, D.H.; Tsai, C.T.; Chen, H.Y.; Kuo, H.C.; Lin, G.R. 450-nm GaN laser diode enables high-speed visible light communication with 9-Gbps QAM-OFDM. Opt. Express 2015, 23, 13051-13059. [CrossRef] [PubMed]

70. Chun, H.; Rajbhandari, S.; Tsonev, D.; Faulkner, G.; Haas, H.; O’Brien, D. Visible light communication using laser diode based remote phosphor technique. In Proceedings of the IEEE International Conference on Communication Workshop, London, UK, 8-12 June 2015; pp. 1392-1397.

71. Chi, Y.C.; Hsieh, D.H.; Lin, C.Y.; Chen, H.Y.; Huang, C.Y.; He, J.H.; Ooi, B.; Denbaars, S.P.; Nakamura, S.; Kuo, H.C. Phosphorous diffuser diverged blue laser diode for indoor lighting and communication. Sci. Rep. 2015, 5. [CrossRef] [PubMed]

72. Retamal, J.R.; Oubei, H.M.; Janjua, B.; Chi, Y.C.; Wang, H.Y.; Tsai, C.T.; Ng, T.K.; Hsieh, D.H.; Kuo, H.C.; Alouini, M.S. 4-Gbit/s visible light communication link based on 16-QAM OFDM transmission over remote phosphor-film converted white light by using blue laser diode. Opt. Express 2015, 23, 33656-33666. [CrossRef] [PubMed]

73. Lee, C.; Shen, C.; Oubei, H.M.; Cantore, M.; Janjua, B.; Ng, T.K.; Farrell, R.M.; El-Desouki, M.M.; Speck, J.S.; Nakamura, S. 2 Gbit/s data transmission from an unfiltered laser-based phosphor-converted white lighting communication system. Opt. Express 2015, 23, 29779-29787. [CrossRef] [PubMed]

74. Manousiadis, P.; Chun, H.; Rajbhandari, S.; Mulyawan, R. Demonstration of 2.3 Gb/s RGB white-light VLC using polymer based colour-converters and GaN micro-LEDs. In Proceedings of the Summer Topicals Meeting Series, Nassau, Bahamas, 13-15 July 2015; pp. 222-223.

75. Cossu, G.; Ali, W.; Corsini, R.; Ciaramella, E. Gigabit-class optical wireless communication system at indoor distances (1.5-4 m). Opt. Express 2015, 23, 15700-15705. [CrossRef] [PubMed]

76. Li, J.; Xu, Y.; Shi, J.; Wang, Y.; Ji, X.; Ou, H.; Chi, N. A $2 \times 2$ imaging MIMO system based on LED visible light communications employing space balanced coding and integrated PIN array reception. Opt. Commun. 2016, 367, 214-218. [CrossRef]

77. Huang, X.; Shi, J.; Li, J.; Wang, Y.; Chi, N. A Gb/s VLC transmission using hardware preequalization circuit. IEEE Photonics Technol. Lett. 2015, 27, 1915-1918. [CrossRef]

78. Chen, T.; Liu, L.; Zheng, Z.; Song, J.; Wu, K.; Hu, W. Fisheye-lens-based space division multiplexing system for visible light communications. Eur. J. Wirel. Commun. Netw. 2015, 2015, 1-7. [CrossRef]

79. Stepniak, G.; Maksymiuk, L.; Siuzdak, J. 1.1 Gbit/s white lighting LED-based visible light link with pulse amplitude modulation and volterra DFE equalization. Microw. Opt. Technol. Lett. 2015, 57, 1620-1622. [CrossRef]

80. Li, H.; Zhang, Y.; Chen, X.; Wu, C.; Guo, J.; Gao, Z.; Pei, W.; Chen, H. 682 Mbit/s phosphorescent white LED visible light communications utilizing analog equalized 16QAM-OFDM modulation without blue filter. Opt. Commun. 2015, 354, 107-111. [CrossRef]

81. Tsonev, D.; Chun, H.; Rajbhandari, S.; Mckendry, J.J.D.; Videv, S.; Gu, E.; Haji, M.; Watson, S.; Kelly, A.E.; Faulkner, G. A 3-Gb/s single-LED OFDM-based wireless VLC link using a gallium nitride $\mu$-LED. IEEE Photonics Technol. Lett. 2014, 26, 637-640. [CrossRef]

82. Chun, H.; Manousiadis, P.; Rajbhandari, S.; Vithanage, D.A.; Faulkner, G.; Tsonev, D.; Mckendry, J.J.D.; Videv, S.; Xie, E.; Gu, E. Visible light communication using a blue GaN $\mu$-LED and fluorescent polymer color converter. IEEE Photonics Technol. Lett. 2014, 26, 2035-2038. [CrossRef] 
83. Wang, Y.; Huang, X.; Zhang, J.; Wang, Y.; Chi, N. Enhanced performance of visible light communication employing 512-QAM N-SC-FDE and DD-IMs. Opt. Express 2014, 22, 15328-15334. [CrossRef] [PubMed]

84. Wang, Y.; Yang, C.; Wang, Y.; Chi, N. Gigabit polarization division multiplexing in visible light communication. Opt. Lett. 2014, 39, 1823-1826. [CrossRef] [PubMed]

85. Chi, N.; Wang, Y. Demonstration of high-speed $2 \times 2$ non-imaging MIMO Nyquist single carrier visible light communication with frequency domain equalization. J. Lightwave Technol. 2014, 32, 2087-2093.

86. Chen, H.; Li, H.; Guo, J.; Chen, X. A 550 Mbit/s real-time visible light communication system based on phosphorescent white light LED for practical high-speed low-complexity application. Opt. Express 2014, 22, 27203-27213.

87. Li, H.; Chen, X.; Huang, B.; Tang, D.; Chen, H. High bandwidth visible light communications based on a post-equalization circuit. IEEE Photonics Technol. Lett. 2014, 26, 119-122. [CrossRef]

88. Burton, A.; Minh, H.L.; Ghassemlooy, Z.; Bentley, E.; Botella, C. Experimental demonstration of 50-Mb/s visible light communications using $4 \times 4$ MIMO. IEEE Photonics Technol. Lett. 2014, 26, 945-948. [CrossRef]

89. Mesleh, R.; Elgala, H.; Little, T.D.C. On the performance degradation of optical wireless OFDM communication systems due to changes in the LED junction temperature. In Proceedings of the 20th International Conference on Telecommunications, Casablanca, Morocco, 6-8 May 2013; pp. 1-5.

90. Chhajed, S.; Xi, Y.; Li, Y.L.; Gessmann, T.; Schubert, E.F. Influence of junction temperature on chromaticity and color-rendering properties of trichromatic white-light sources based on light-emitting diodes. J. Appl. Phys. 2005, 97. [CrossRef]

91. Narendran, N.; Gu, Y. Life of LED-based white light sources. J. Disp. Technol. 2005, 1, 167-171. [CrossRef]

92. Komine, T.; Haruyama, S.; Nakagawa, M. Bidirectional visible-light communication using corner cube modulatior. Tech. Rep. Ieice Dsp. 2003, 102, 41-46.

93. Hou, J.; O'Brien, D.C. Vertical Handover-Decision-Making Algorithm Using Fuzzy Logic for the Integrated Radio-and-Ow System. IEEE Trans. Wireless Commun. 2006, 5, 176-185.

94. Liu, Y.F.; Yeh, C.H.; Chow, C.W.; Liu, Y.; Liu, Y.L.; Tsang, H.K. Demonstration of bi-directional LED visible light communication using tdd traffic with mitigation of reflection interference. Opt. Express 2012, 20, 23019-23024. [CrossRef] [PubMed]

95. Borogovac, T.; Rahaim, M.B.; Tuganbayeva, M.; Little, T.D.C. "Lights-off" visible light communications. In GLOBECOM Workshops; IEEE: Houston, TX, USA, 2012; pp. 797-801. 